\title{
SARS-Cov-2 prevalence, transmission, health-related outcomes and control strategies in homeless shelters: Systematic review and meta- analysis
}

\author{
Amir Mohsenpour ${ }^{\mathrm{a}, \mathrm{b}, *}$, Kayvan Bozorgmehr $^{\mathrm{a}, \mathrm{b}}$, Sven Rohleder ${ }^{\mathrm{a}, \mathrm{b}}$, Jan Stratil $^{\mathrm{c}}$, Diogo Costa ${ }^{\mathrm{a}}$ \\ ${ }^{a}$ Department of Population Medicine and Health Services Research, School of Public Health, Bielefeld University, P.0. Box: 1001 31, 33501 Bielefeld, Germany \\ ${ }^{\mathrm{b}}$ Section for Health Equity Studies and Migration, Department of General Practice and Health Services Research, Heidelberg University Hospital, Germany \\ ${ }^{c}$ Institute for Medical Informatics, Biometry and Epidemiology, Ludwig-Maximilians-University Munich, Germany
}

\section{A R T I C L E I N F O}

\section{Article History:}

Received 8 January 2021

Revised 2 July 2021

Accepted 2 July 2021

Available online $\mathrm{xxx}$

\section{Keywords:}

people experiencing homelessness

homeless shelters

SARS-CoV-2

COVID-19

systematic review

Meta-analysis

\begin{abstract}
A B S T R A C T
Background: People experiencing homelessness (PEH) may be at risk for COVID19. We synthesised evidence on SARS-Cov-2 infection, transmission, outcomes of disease, effects of non-pharmaceutical interventions (NPI), and the effectiveness of strategies for infection prevention and control (IPC).

Methods: Systematic review of articles, indexed in electronic databases (EMBASE, WHO-Covid19, Web of Science), institutional websites and the Norwegian Institute of Public Health's live map of COVID-19 evidence, and published from December 1st, 2019, to March 3rd, 2021. Empirical papers of any study design addressing Covid-19 and health(-related) outcomes in PEH or shelters' staff were included. (PROSPERO2020-CRD42020187033)

Findings: Of 536 publications, 37 studies were included (two modelling, 31 observational, four qualitative studies). Random-effect meta-analysis yields a baseline SARS-Cov-2 prevalence of $2 \bullet 32 \%$ (95\% ConfidenceInterval, $95 \% \mathrm{Cl}=1 \bullet 30-3 \bullet 34)$ in $\mathrm{PEH}$ and $1 \bullet 55 \%(95 \% \mathrm{Cl}=0 \bullet 79-2 \bullet 31)$ in staff. In outbreaks, the pooled prevalence increases to $31 \bullet 59 \%(95 \% \mathrm{Cl}=20 \bullet 48-42 \bullet 71)$ in $\mathrm{PEH}$ and $14 \bullet 80 \%(95 \% \mathrm{Cl}=10 \bullet 73-18 \bullet 87)$ in staff. Main IPC strategies were universal rapid testing, expansion of non-congregate housing, and in-shelter measures (bed spacing, limited staff rotation, reduction in number of residents).

Interpretation: $32 \%$ of PEH and 15\% staff are infected during outbreaks of SARS-Cov-2 in homeless shelters. Most studies were conducted in the USA. No studies were found quantifying health-related outcomes of NPI. Overview and evaluation of IPC strategies for PEH, a better understanding of disease transmission, and reliable data on PEH within Covid-19 notification systems are needed. Qualitative studies may serve to voice PEH and shelter staff experiences, and guide future evaluations and IPC strategies.
\end{abstract}

(c) 2021 The Author(s). Published by Elsevier Ltd. This is an open access article under the CC BY-NC-ND license (http://creativecommons.org/licenses/by-nc-nd/4.0/)

\section{Introduction}

Homelessness is associated with mental health problems [1,2], infectious diseases [3], cardiovascular and respiratory diseases, and several long-term conditions (e.g., asthma, COPD, epilepsy) [4]. People experiencing homelessness (PEH) are a diverse group categorized according to their living situation: (a) Rooflessness, people without shelter sleeping rough in the streets or in public spaces, (b) houselessness, with accommodation of temporary nature, (c) living in insecure housing, shaped by threats of insecure tenancy, eviction

\footnotetext{
Funding No funding source.
}

* Corresponding author at: Department of Population Medicine and Health Services Research, School of Public Health, Bielefeld University, P.O. Box: 1001 31, 33501 Bielefeld, Germany.

E-mail address: amir.mohsenpour@uni-bielefeld.de (A. Mohsenpour). or domestic violence, and (d) living in inadequate housing, e.g. in caravans on illegal campsites or in extreme overcrowding [5,6].

The policy measures taken to mitigate the spread of the SARSCov-2 pandemic, such as physical distancing and national lockdowns, may have aggravated their health and social conditions, adding to their already marginalised situation [7-9].

Typical means of survival in daily life of PEH were disrupted, e.g. food banks and other basic aid facilities were shut-down, temporary housing projects were halted [8]. It is unclear how PEH dealt with the generalised closure of institutions, restrictions in movements and public transports, or how they perceived and adhered to the measures imposed, such as the use of nose and mouth protection.

PEH are vulnerable to SARS-Cov-2 infection due to the risk of transmission in shared accommodations, comorbidities and lower immune-response because of poor nutrition and food insecurity. Yet, evidence is scarce about the risk of infection among $\mathrm{PEH}$, their 


\section{Research in context}

\section{Evidence before this study}

People experiencing homelessness (PEH) are at increased risk of infectious, chronic, and mental health adverse conditions. Due to the risk of transmission in shared accommodations, PEH may be particularly vulnerable to SARS-Cov-2 infection and worse clinical outcomes. Non-pharmaceutical interventions (NPIs) taken to mitigate the SARS-Cov-2 outbreak may have further aggravated health and social conditions. However, there is no evidence synthesis on the SARS-Cov-2 epidemiology among PEH, the correspondent clinical and other health-related outcomes as well as health effects of NPIs on these groups.

\section{Added value of this study}

We reviewed and synthesized existent evidence on the risk of infection and transmission, risk of severe course of disease, effect of NPIs on health outcomes and the effectiveness of implemented measures to avert risks and negative outcomes among PEH. Results of the identified studies suggest that both PEH and shelter staff are at high risk of SARS-Cov-2 infection, especially in case of a local outbreak. Due to the low prevalence of symptoms at the time of a positive SARS-Cov-2 test among $\mathrm{PEH}$, symptom screening alone may not be efficient to control outbreaks. Instead, universal and rapid testing conjugated with expansion of non-congregate housing support, and individual measures in shelters, are discussed as sensible strategies.

\section{Implications of all the available evidence}

A comprehensive overview of NPIs and shelter strategies targeting PEH and evaluation of their effectiveness and unintended health consequences is needed. Further qualitative research considering living realities of PEH can facilitate understanding of their specific needs during the pandemic.

differential susceptibility and health outcomes observed during the pandemic, to inform the design of infection protection and control (IPC) strategies.

We aimed to synthesize the evidence on the risk of infection and transmission, risk of severe course of disease, effect of non-pharmaceutical interventions (NPI) on health outcomes and IPC strategies to avert risks and negative outcomes among PEH.

\section{Methods}

\subsection{Search strategy and selection criteria}

The systematic review was guided by five specific research questions:

1. What is the prevalence or incidence of infection with SARS-CoV-2 in homeless shelters?

2. What is the evidence on transmission among PEH in different settings (e. g. in homeless shelters, at outreach events, when sleeping rough on the street)?

3. What are clinical and other health-related outcomes of the disease among PEH (e. g. measured by hospitalisation, ICU, ventilation, mortality)?

4. What is the evidence on the effects of lockdown measures and other non-pharmacological interventions on the health status of $\mathrm{PEH}$ ?

5. What is the evidence on the effects of policies/strategies specifically enacted for PEH?
We developed and registered a review protocol in PROSPERO (PROSPERO registration 2020 CRD42020187033) [10], and followed the recommendations of the taskforce on guidelines for systematic reviews in health promotion and public health [11]. To answer these questions, we conducted a systematic search of scientific databases for peer-reviewed articles in EMBASE, the WHO Covid19 database, and Web of Science Core Collection, the Norwegian Institute of Public Health's live map of COVID-19 evidence, websites of relevant institutions and two not-indexed journals, including reference snowballing (search strategy details presented in supplementary material 1).

A PICO framework was used to help define the inclusion/exclusion criteria: population was defined as PEH fitting the FEANTSA-ETHOS definitions; empirical quantitative, qualitative and mixed-methods studies, documenting exposure to SARS-Cov-2 or any policy measure or specific IPC strategies for PEH during the Pandemic were included; the general population was considered the standard for comparison, although a comparison group was not a criteria for inclusion; outcomes could be any health-related effect of SARS-Cov-2, including prevalence, incidence, evidence on transmission, development of disease, risk of severe course of disease, hospitalisation, ICU utilization, ventilation, or mortality. Effects of lockdown and other NPIs on the health status of PEH were also considered.

Empirical studies in English published in peer-reviewed journals, indexed from December 1st 2019 onwards, were included, and the searches were conducted on March 3rd 2021

\subsection{Data analysis}

Titles and abstracts were screened by two independent researchers (AM, DC) applying pre-defined inclusion/exclusion criteria. After screening $20 \%$, the review team refined the criteria for the remaining articles, namely by deciding to not include studies focused on PEH's health but not explicitly considering any Covid-19/SARS-Cov-2 related issue. Full texts were obtained for all included studies and for those where no agreement could be established based on title/ abstracts alone. For all included full text articles, backward and forward citation search was conducted (PRISMA Flowchart Fig. 1).

We extracted relevant parameters from cross-sectional quantitative studies to synthesise a pooled measure of SARS-Cov-2 prevalence. For this meta-analysis, we assumed that prevalences are randomly sampled from a distribution and thus applied a randomeffects approach in place of a fixed-effect model which would have assumed one fixed population prevalence [12].

In addition to the Q-statistic, assessing the null hypothesis that all studies share a common prevalence, we calculated $\mathrm{I}^{2}$, assessing the proportion of variance due to heterogeneity rather than chance, $\tau^{2}$, assessing dispersion between studies, and the $95 \%$ prediction intervals of the true prevalences to explore heterogeneity [12-14].

As some studies may report prevalence estimates of people experiencing rooflessness and staff, we conducted a second metaanalysis including these.

The extracted data were stratified based on the presence of an outbreak situation during data collection, either marked as such by authors or based on a prevalence above a pre-defined outbreak threshold, i.e. the proportion of infected individuals after which an outbreak is unlikely to go extinct without an external intervention or before infecting the full population [15]. As these thresholds are based on previous data, we chose the lowest reported prevalence measure (9\% [16]) and decided on rounding down to an even lower threshold of $5 \%$ to be conservative. Further, risk of bias and publication bias were assessed through funnel plots and regression-based statistical testing by Egger et al. [17,18].

Stata V16 [19] with commands metaprop [20] and meta [21] were used for the analysis. 


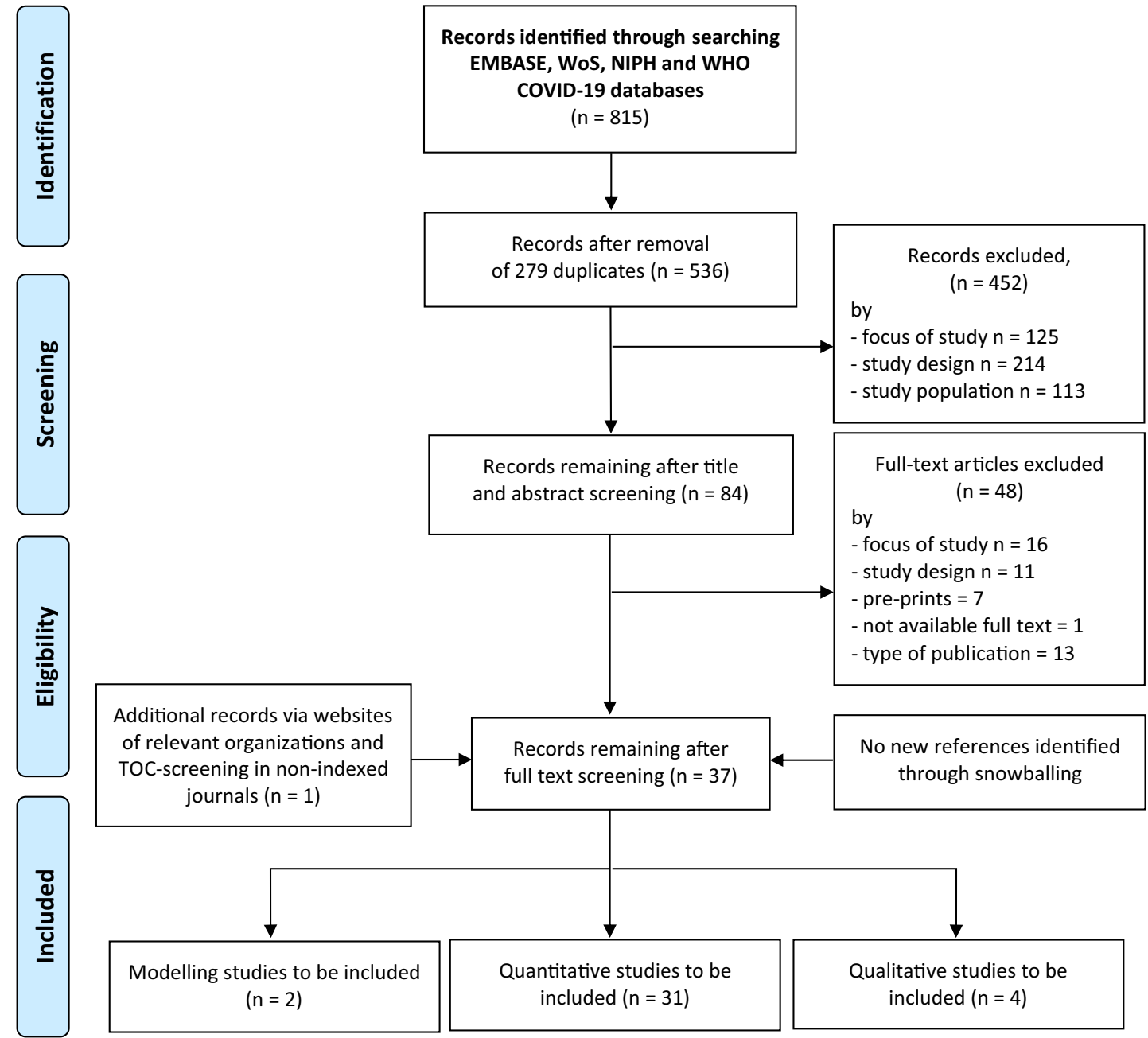

Fig. 1. PRISMA 2009 flow diagrams.

\subsection{Role of the funding source}

This research did not receive any specific grant from funding agencies in the public, commercial, or not-for-profit sectors.

\section{Results}

After duplicates removal, 536 title and abstracts were eligible for screening. 84 studies were included for full-text screening and 36 included in analysis. The manual screening of relevant websites and non-indexed journals resulted in one additional study to be included.

Information was thus extracted from 31 quantitative studies (two cohorts, one interrupted time series and 28 cross-sectional), two modelling studies and four qualitative studies (PRISMA Flowchart Fig. 1) [22].

19 quantitative studies were conducted in the USA [23-41], three in Canada [42-44],three in France [16,45,46], two in Italy [47,48], and one in Belgium [49], Spain [50], Slovakia [51], and Denmark [52], respectively. The data collection period considering all studies ranged from January 2020 to October 2020.

All studies focused on people experiencing houselessness (i.e. with a place to sleep but temporary in institutions or shelter according to FEANTSA-ETHOS definitions [5,6]), though not always clearly defined, with two studies [35,53] additionally covering people experiencing rooflessness (i.e. sleeping rough). 21 articles reported PCR-based estimates of SARS-Cov-2 prevalence with some offering additional data on other health or living conditions of homeless people.

A total of ten articles reported prevalence estimates for staff working at the homeless facilities [16,23,25,31,35-37,42].

All study characteristics are presented in Table 1. Risk of bias assessment is presented in table 2 .

\subsection{Prevalence of SARS-Cov2 in homeless shelters}

We found 16 quantitative articles reporting PCR-based SARS-Cov2 prevalence estimates in PEH and ten studies reporting prevalence estimates for shelter staff members. To adjust for the varying settings and contexts, we pooled the measures in a random-effects metaanalysis model for PEH $(n=21280)$ and staff $(n=1662)$. To consider the difference in nature of investigating an outbreak $[16,23,24,36,37,39]$ and testing for estimation of a baseline prevalence $[16,23,34,35,42]$ in our meta-analysis, we sub-pooled the measures accordingly.

For PEH, the pooled SARS-Cov-2 prevalence estimate was $31.59 \%$ (95\% Confidence Interval, 95\% Cl=20.48\%-42.71\%, $\tau^{2}=314.94$, $\mathrm{I}^{2}=98.76 \%$ ) in the context of outbreak situations. In case of no acute outbreak, the pooled baseline prevalence was $2.32 \% \quad(95 \%$ $\mathrm{CI}=1 \cdot 30 \%-3 \cdot 34 \%, \tau^{2}=1 \cdot 33, \mathrm{I}^{2}=92 \cdot 86 \%$ ) (Fig. $2 \mathrm{a}$ ).

The second meta-analysis $(n=51226)$ including articles where staff [47], people with recent history of homelessness [43] and other vulnerable populations (such as refugees or substance users) [52] 


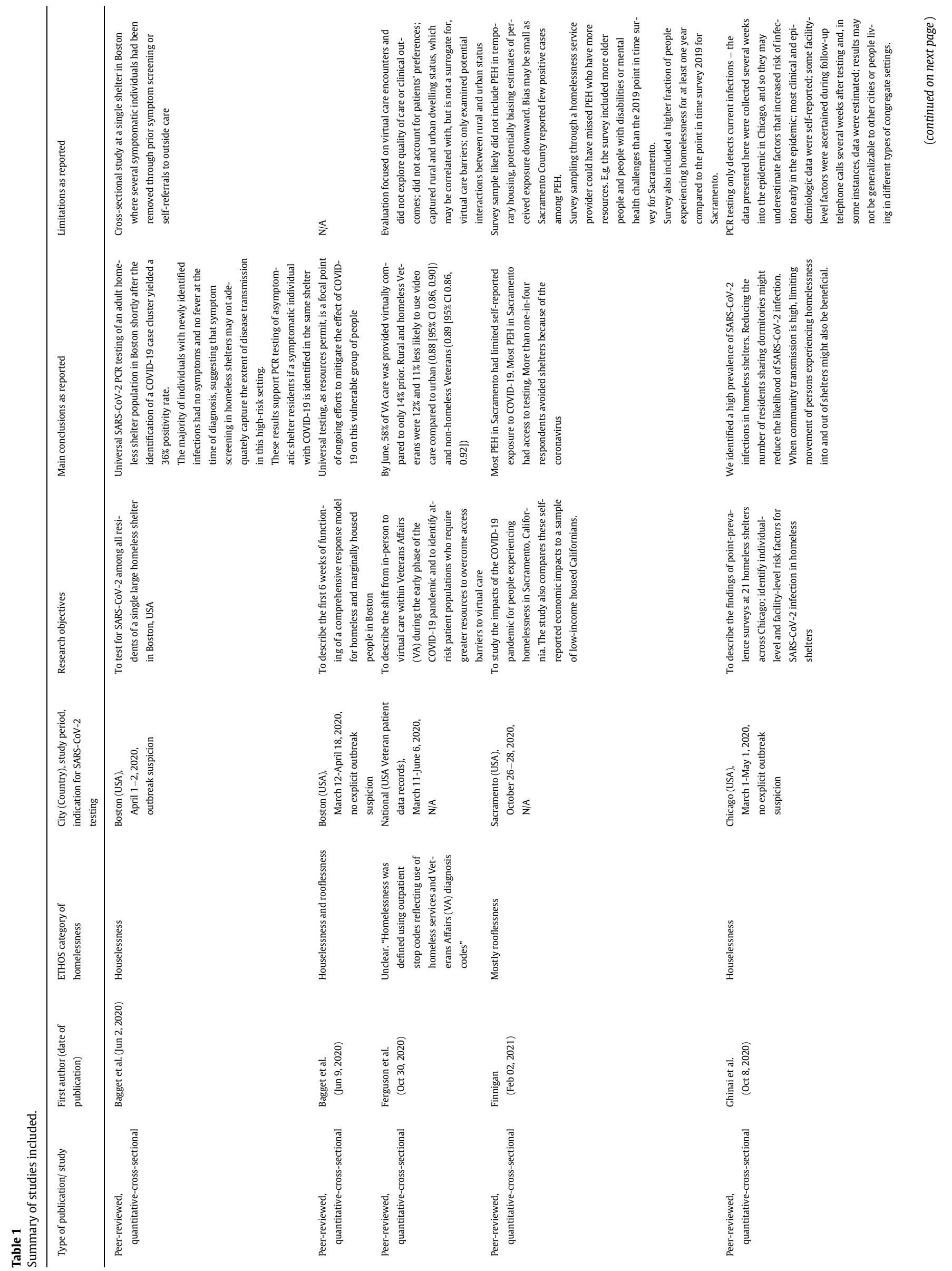




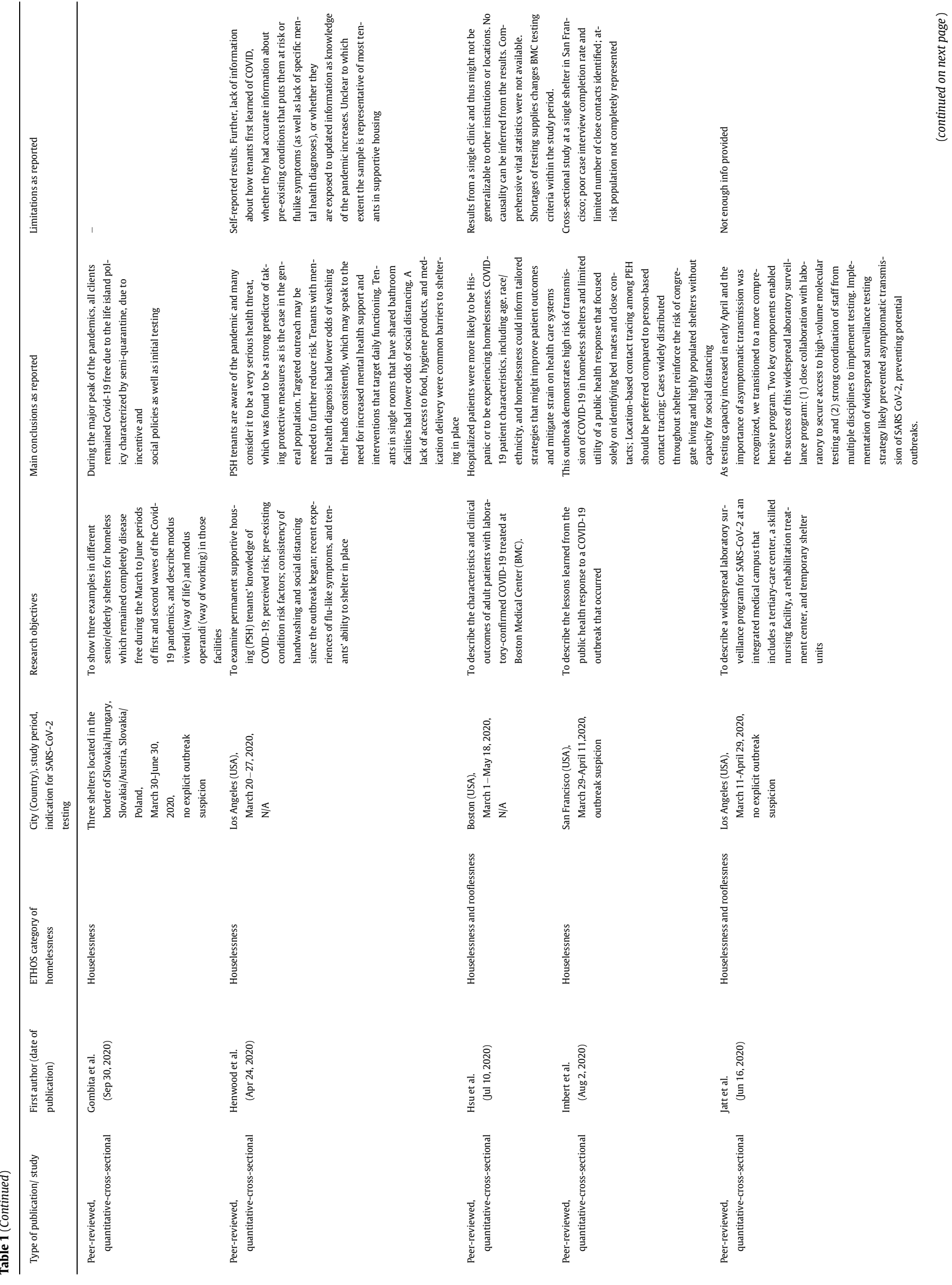




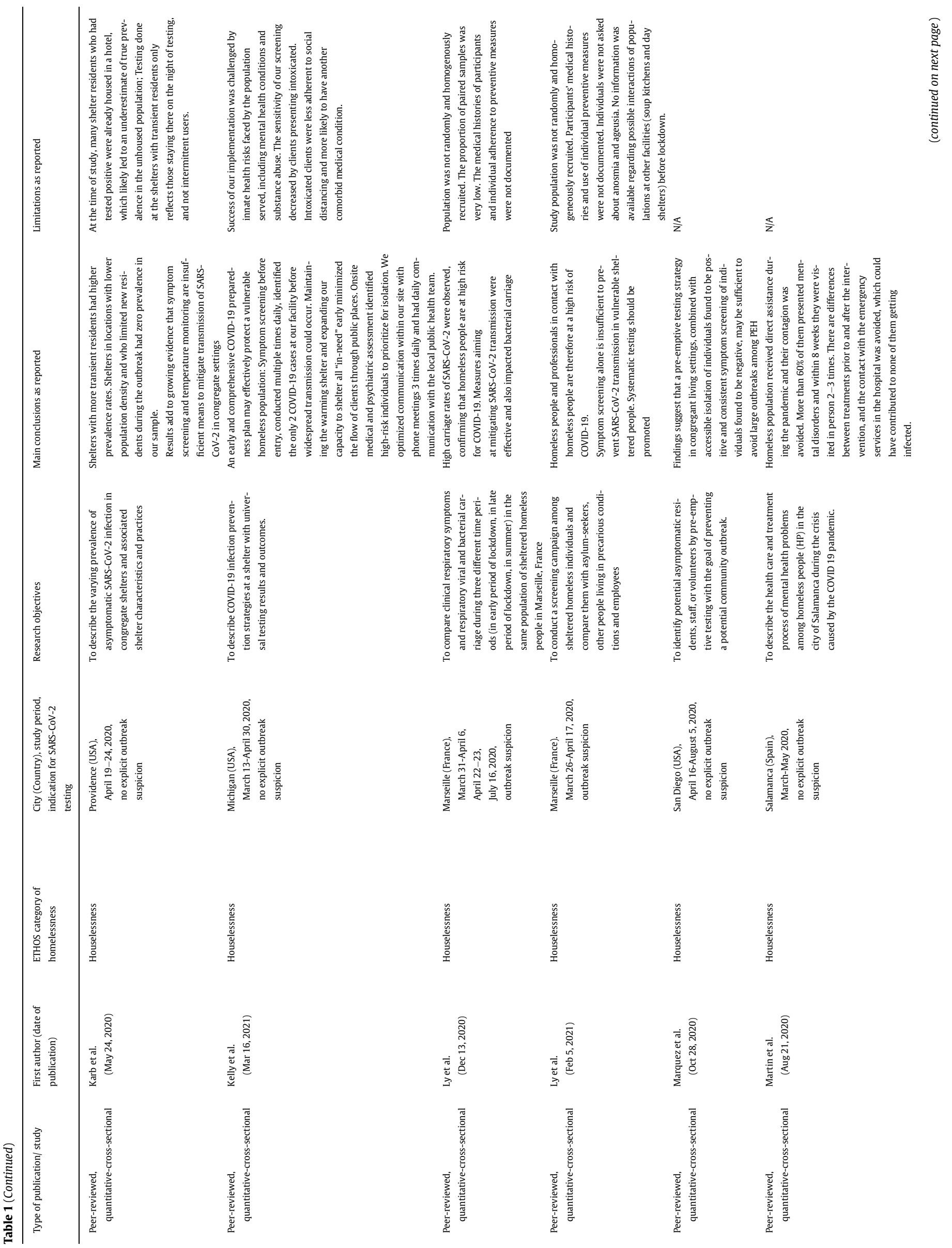









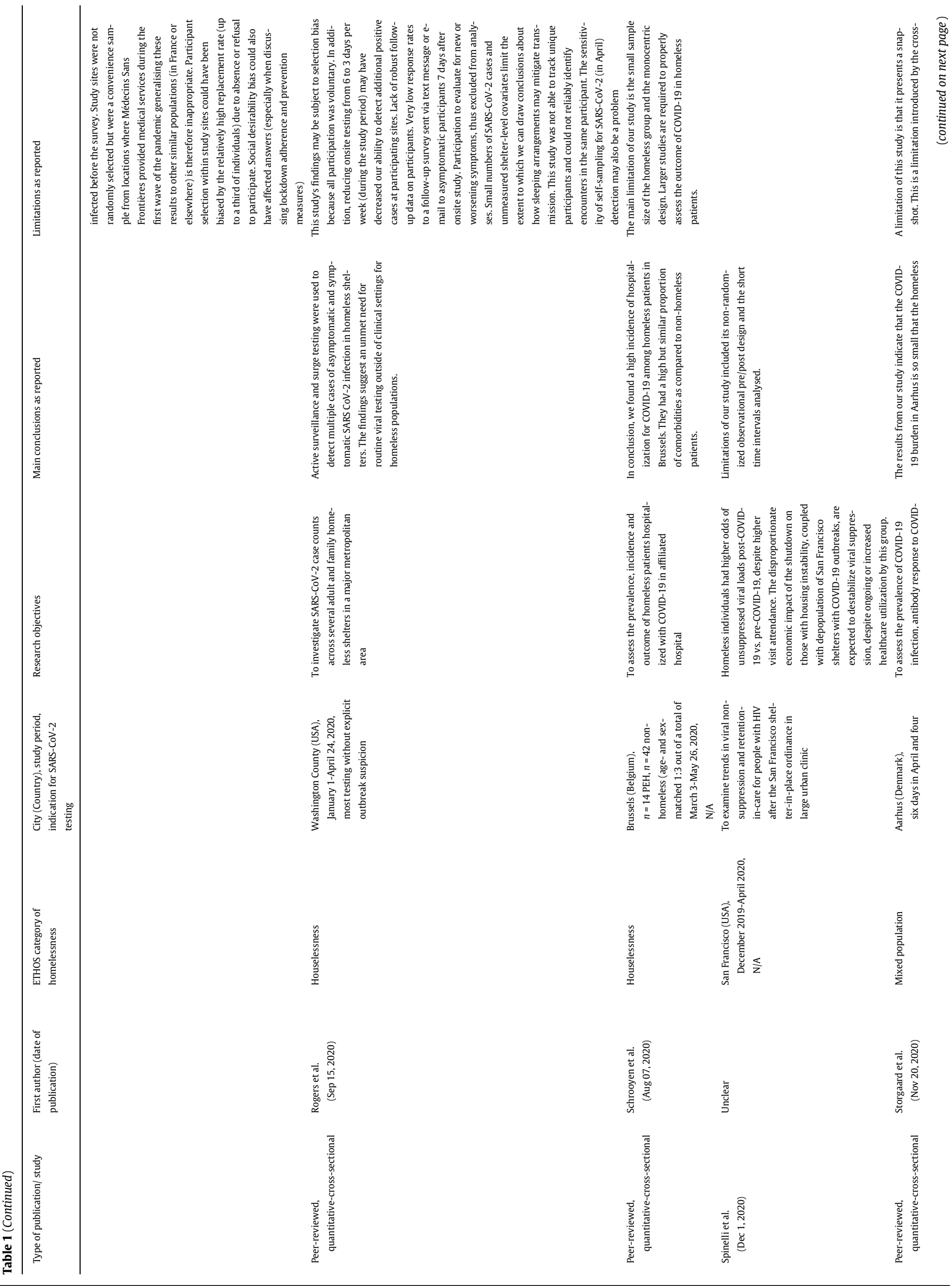




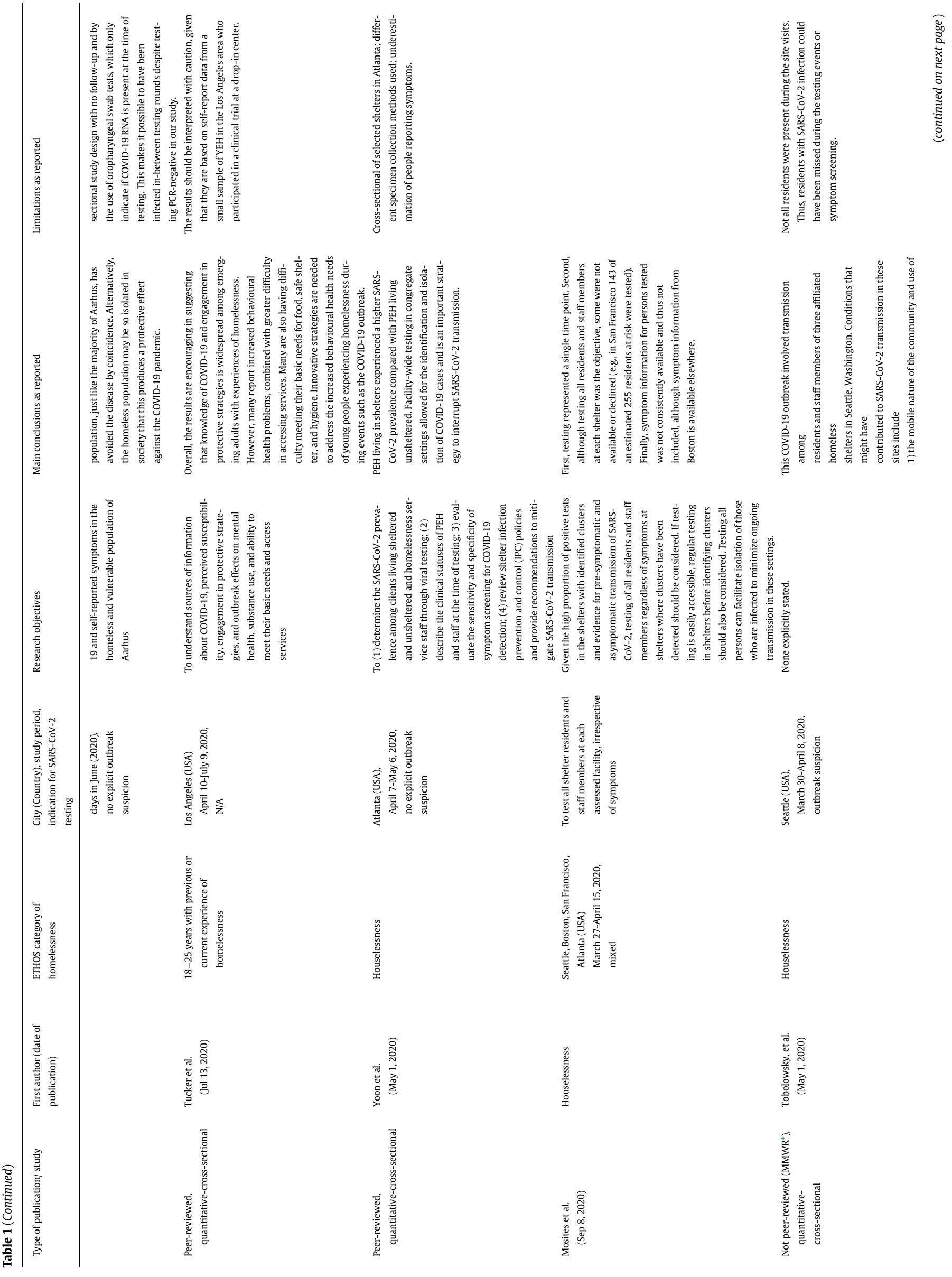




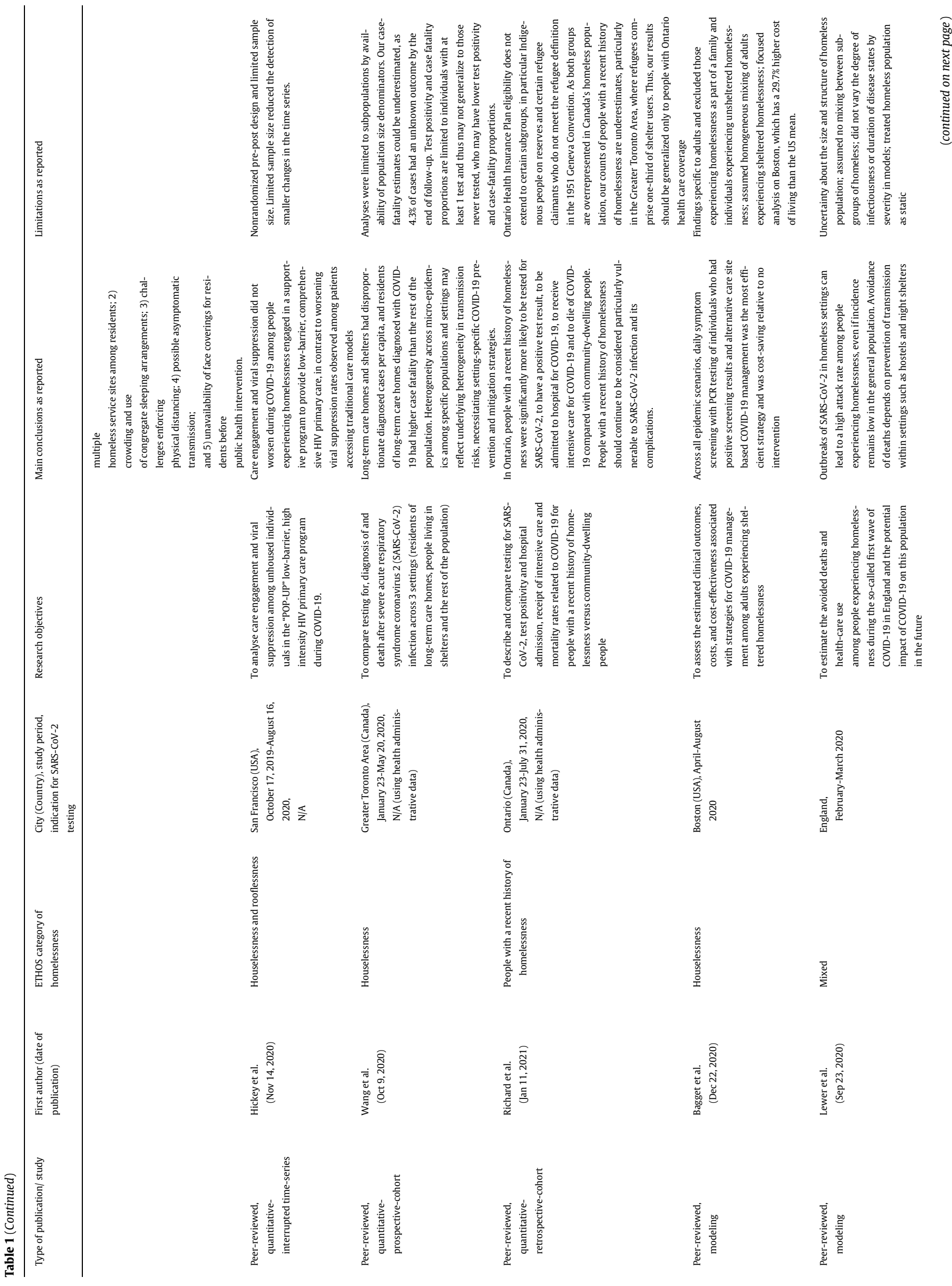


Table 2

Risk of bias assessment of included studies

\section{Quantitative cross-sectional}

\begin{tabular}{|c|c|c|c|c|c|}
\hline $\begin{array}{c}\text { Study author } \\
\text { (date of publication) }\end{array}$ & 这 & 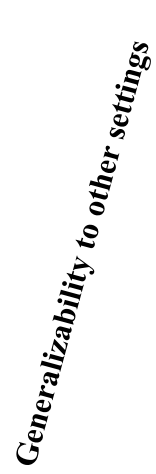 & : & 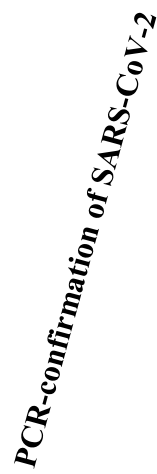 & 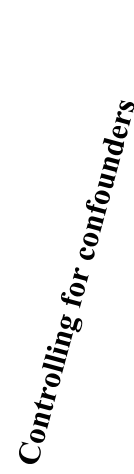 \\
\hline Bagget et al. (Jun 2, 2020) & + & - & + & + & $\mathrm{N} / \mathrm{A}$ \\
\hline Bagget et al. (Jun 9, 2020) & + & + & $?$ & + & N/A \\
\hline Ferguson et al. (Oct 30, 2020) & + & + & + & N/A & + \\
\hline Finnigan (Feb 02, 2021) & + & - & - & N/A & $\mathrm{N} / \mathrm{A}$ \\
\hline Ghinai et al. (Oct 8,2020$)$ & + & + & + & + & + \\
\hline Gombita et al. (Sep 30, 2020) & + & - & + & + & N/A \\
\hline Henwood et al. (Apr 24, 2020) & + & - & + & N/A & + \\
\hline Hsu et al. (Jul 10, 2020) & + & - & + & + & - \\
\hline Imbert et al. (Aug 2, 2020) & + & - & + & + & $\mathrm{N} / \mathrm{A}$ \\
\hline Jatt et al. (Jun 16, 2020) & + & - & + & + & $\mathrm{N} / \mathrm{A}$ \\
\hline Karb et al. (May 24, 2020) & + & + & + & + & - \\
\hline Kelly et al. (Mar 16, 2021) & + & - & + & + & $\mathrm{N} / \mathrm{A}$ \\
\hline Ly et al. (Dec 13, 2020) & + & - & + & + & - \\
\hline Ly et al. (Feb 5, 2021) & + & - & + & + & + \\
\hline Marquez et al. (Oct 28,2020$)$ & + & - & $?$ & + & $\mathrm{N} / \mathrm{A}$ \\
\hline Martin et al. (Aug 21, 2020) & + & - & + & $\mathrm{N} / \mathrm{A}$ & $\mathrm{N} / \mathrm{A}$ \\
\hline
\end{tabular}




\begin{tabular}{|c|c|c|c|c|c|}
\hline O'Shea et al. (Jun 8, 2020) & + & + & + & + & N/A \\
\hline \multicolumn{6}{|l|}{ Qualitative } \\
\hline Ralli et al. (Nov 29, 2020) & + & - & $?$ & - & $\mathrm{N} / \mathrm{A}$ \\
\hline Ralli et al. (Dec 10, 2020) & + & $?$ & + & + & $\mathrm{N} / \mathrm{A}$ \\
\hline Roederer et al. (Feb 05, 2021) & + & + & + & + & + \\
\hline Rogers et al. (Sep 15, 2020) & + & + & + & + & $\mathrm{N} / \mathrm{A}$ \\
\hline Schrooyen et al. (Aug 07, 2020) & + & - & + & + & - \\
\hline Spinelli et al. (Dec 1, 2020) & + & - & + & N/A & + \\
\hline Storgaard et al. (Nov 20, 2020) & + & + & $?$ & + & $\mathrm{N} / \mathrm{A}$ \\
\hline Tucker et al. (Jul 13, 2020) & + & - & + & N/A & $\mathrm{N} / \mathrm{A}$ \\
\hline Yoon et al. (May 1,2020 ) & + & + & + & + & N/A \\
\hline
\end{tabular}

\section{MMWR}

\begin{tabular}{|c|c|c|c|c|c|}
\hline Mosites et al. (Sep 8, 2020) & + & + & + & + & $\mathrm{N} / \mathrm{A}$ \\
\hline Tobolowsky, et al. (May 1, 2020) & + & + & + & + & $\mathrm{N} / \mathrm{A}$ \\
\hline
\end{tabular}

\section{Other quantitative}

\begin{tabular}{|c|c|c|c|c|c|}
\hline Hickey et al. (Nov 14, 2020) & + & - & + & N/A & - \\
\hline Wang et al. (Oct 9, 2020) & + & + & + & + & + \\
\hline Richard et al. (Jan 11, 2021) & + & + & + & + & + \\
\hline $\begin{array}{l}\text { "+" = yes } \\
" ? "=\text { unclear } \\
\text { "_" = no }\end{array}$ & & & & & \\
\hline
\end{tabular}

"N/A" not applicable $\mid M M W R=$ Morbidity and Mortality Weekly Report by CDC

may have been included resulted in a pooled base prevalence of $2.34 \%\left(95 \% \mathrm{Cl}=1.44 \%-3.25 \%, \tau^{2}=1.46, \mathrm{I}^{2}=95.98 \%\right)$ which increased $31.59 \%\left(95 \% \mathrm{Cl}=20.48 \%-42 \cdot 71 \%, \tau^{2}=314.94, \mathrm{I}^{2}=98.76 \%\right)$ in case of an outbreak (Fig. 2b).

For staff members, the random-effect meta-analysis resulted in a pooled prevalence of $14 \cdot 80 \%\left(95 \% \mathrm{CI}=4 \cdot 22 \%-13 \cdot 57 \%, \tau^{2}=10 \cdot 19\right.$, $\left.\mathrm{I}^{2}=43.58 \%\right)$ during an outbreak situation and $1.55 \%(95 \%$ $\left.\mathrm{Cl}=0.79 \%-2.31 \%, \tau^{2}=0.00, \mathrm{I}^{2}=0.00 \%\right)$ for baseline estimation (Fig. 3).

Funnel plots of studies reporting SARS-Cov-2 prevalence and corresponding standard errors are presented in supplementary material 2. The Egger test suggests absence of significant publication bias in all strata except for the overall prevalence among PEH and staff, which both disappears after stratification by outbreak situation (supplementary material 2), supporting the differentiation between baseline estimation and outbreak investigation.

\subsection{Transmission among $P E H$}

In their modelling study for England, Lewer et al. [54] conclude that SARS-Cov-2 outbreaks in homeless shelters can lead to a high attack rate if unmitigated, despite low incidence in the general population. Four studies assessed the proportion of pre-/asymptomatic but seropositive cases in homeless shelters and found no symptoms at time of testing in $68-85 \%$ of the cases $[31,46,47,55]$.

Additionally, while most studies tested PEH in homeless shelters, one study by Yoon et al. [35] conducted additional testing of clients living unsheltered during homeless outreach service events (e.g. 


\begin{tabular}{|c|c|c|c|c|c|}
\hline $\begin{array}{c}\text { Study author } \\
\text { (date of publication) }\end{array}$ & 离 & 离 & 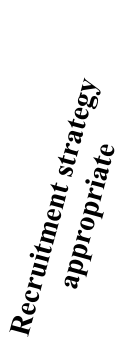 & 离离 & \\
\hline De Paula et al. (Aug 22, 2020) & + & + & + & - & + \\
\hline Marcus et al. (Aug 24, 2020) & + & + & $\mathrm{N} / \mathrm{A}$ & N/A & + \\
\hline Ramaswamy et al. (May 8, 2020) & + & $?$ & $?$ & - & + \\
\hline $\begin{array}{l}\text { Redondo-Sama et al. (Oct 16, } \\
2020 \text { ) }\end{array}$ & + & + & + & + & + \\
\hline $\begin{array}{l}\text { "+" = yes } \\
\text { "?"= unclear } \\
\text { "-" = no } \\
\text { "N/A" not applicable }\end{array}$ & & & & & \\
\hline
\end{tabular}

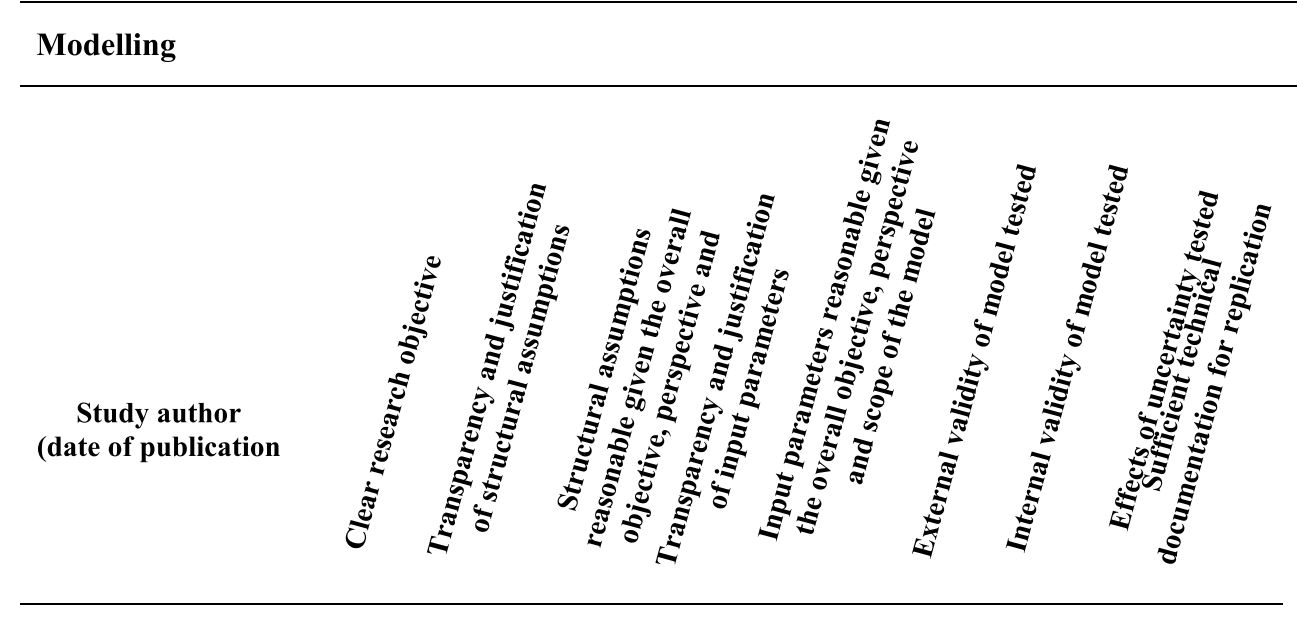

\begin{tabular}{|c|c|c|c|c|c|c|c|c|c|}
\hline $\begin{array}{l}\text { Bagget et al. } \\
\text { (Dec 22, 2020) }\end{array}$ & + & + & + & + & + & ? & + & ? & + \\
\hline $\begin{array}{l}\text { Lewer et al. } \\
\text { (Sep 23, 2020) }\end{array}$ & + & + & + & + & + & $?$ & + & + & + \\
\hline
\end{tabular}

meal services). This resulted in a prevalence of $0.5 \%$ ( 3 out of 636 ) in the unsheltered PEH.

\subsection{Clinical and health-related outcomes among PEH}

Twelve articles [16,24-26,33,35,38,39,41,50,52,56] presented data on clinical outcomes of $\mathrm{PEH}$, ranging from respiratory symptoms to previous mental health diagnosis and other somatic issues (e.g. chronic kidney or liver disease), and one article [36] provided data on emergency department visits, hospitalization and mortality. One article [49] identified homeless within hospitalized symptomatic SARSCOV-2 positive patients in Belgium and found increased odds of smoking, alcoholism, methadone use, and neurological diseases for homeless $(n=14)$ compared with non-homeless patients $(n=42)$. 
Seven articles [24,31,35,36,39,47,48,52] provided data specifically for PEH testing positive: specific symptoms (cough, shortness of breath, fever) were either uncommon or did not differ significantly from the overall tested population of PEH. Neither did comorbidities [39]. Imbert et al. [36] used a city-wide administrative database and reported $12 \%$ ( $n=12)$ of those tested positive to have had a treatment and release emergency department visit, $8 \%(n=8)$ a hospitalization and $1 \%(n=1)$ died.

An analysis conducted at the Boston Medical Centre[28] with patients treated for Covid-19 found that one in five patients hospitalized were experiencing homelessness. When classified by clinical severity the share of PEH among all admitted patients was highest among non-intensive care unit (ICU) with $24.3 \%$, compared to $15.9 \%$ among ICU hospitalizations without mechanical ventilation, $15.1 \%$ among ICU hospitalizations with mechanical ventilation, and $15.3 \%$ among those who died.

A retrospective registry-based analysis conducted in Ontario, Canada [43] (from March to June 2020) identified 30,000 people with a recent history of homelessness and found that SARS-CoV-2 testing, test positivity and hospital admission, intensive care and mortality rates related to Covid-19 were all higher among this group compared to the community dwelling population.

Yoon et al. calculated sensitivity and specificity of symptom screening compared to RT-PCR, stating that fever, cough, or shortness of breath were $14 \%$ sensitive and $89 \%$ specific for identifying
COVID-19 cases when reported in the previous day, changing to $24 \%$ and $85 \%$ when reported in the previous week. An expansion to any symptom reported resulted in no improvement of sensitivity, but a loss in specificity.

Two studies modelled different health-related outcomes among PEH with one conducted for England [54] and one for the USA [57].

\subsection{Non-pharmaceutical interventions (NPI)}

One study [41] looked at the shift from in-person to virtual care within Veterans Affairs (VA) records in the US during the pandemic. The authors characterized $4 \%$ of their sample (out of approx. 5.4 million records) as homeless, and identified this group as being $11 \%$ less likely to use video care compared to non-homeless Veterans.

One qualitative study [58] conducted unstructured interviews through telephone or social media conversations with 35 participants from a US cohort study of criminal justice-involved women to explore how they were faring during this period. Thirteen of the interviewees reported some form of homelessness, and for some of the women their unstable living situations prevented them from being able to follow the social distancing recommended.

Another qualitative study conducted in South Africa described the adaption to a Stadium to serve as the main mass temporary shelter for homeless people during the lockdown in the City of Tshwane [59]. The authors conducted interviews with healthcare professionals

\section{SARS-Cov-2 prevalence in people experiencing homelessness}

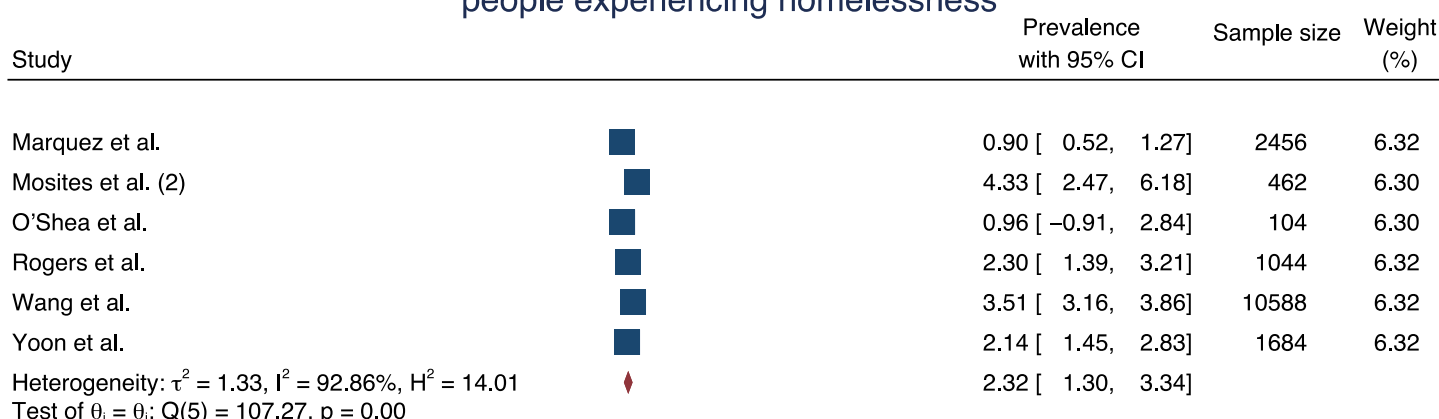

Test of $\theta_{i}=\theta_{j}: Q(5)=107.27, p=0.00$

$95 \%$ prediction interval: $[-1.192,5.827]$

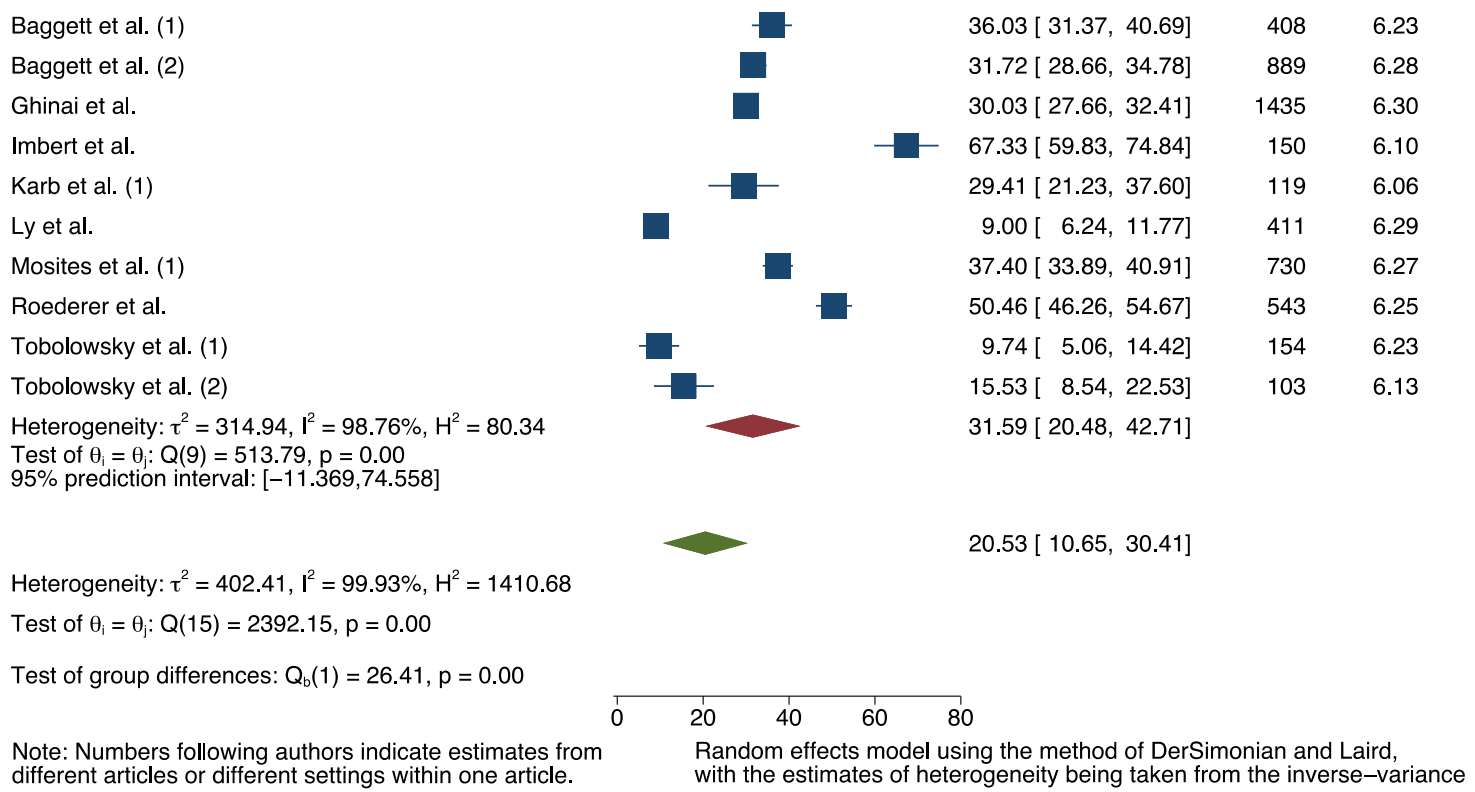

Fig. 2. a: Forest plot of SARS-Cov-2 prevalence pooled by outbreak situation and in total for PEH

b: Forest plot of SARS-Cov-2 prevalence pooled by outbreak situation and in total for PEH - broader inclusion. 


\section{SARS-Cov-2 prevalence in \\ people experiencing homelessness \\ (broad inclusion)}

Study

Marquez et al.

Mosites et al. (2)

O'Shea et al.

Ralli et al. (1)

Richard et al.

Rogers et al.

Storgaard et al. (2)

Wang et al.

Yoon et al.

Heterogeneity: $\tau^{2}=1.46, \mathrm{I}^{2}=95.98 \%, \mathrm{H}^{2}=24.85$

Test of $\theta_{\mathrm{i}}=\theta_{\mathrm{i}}: \mathrm{Q}(8)=225.69, \mathrm{p}=0.00$

$95 \%$ prediction interval: $[-0.712,5.401]$
Prevalence sample size Weight

with $95 \% \mathrm{Cl}$ (\%)

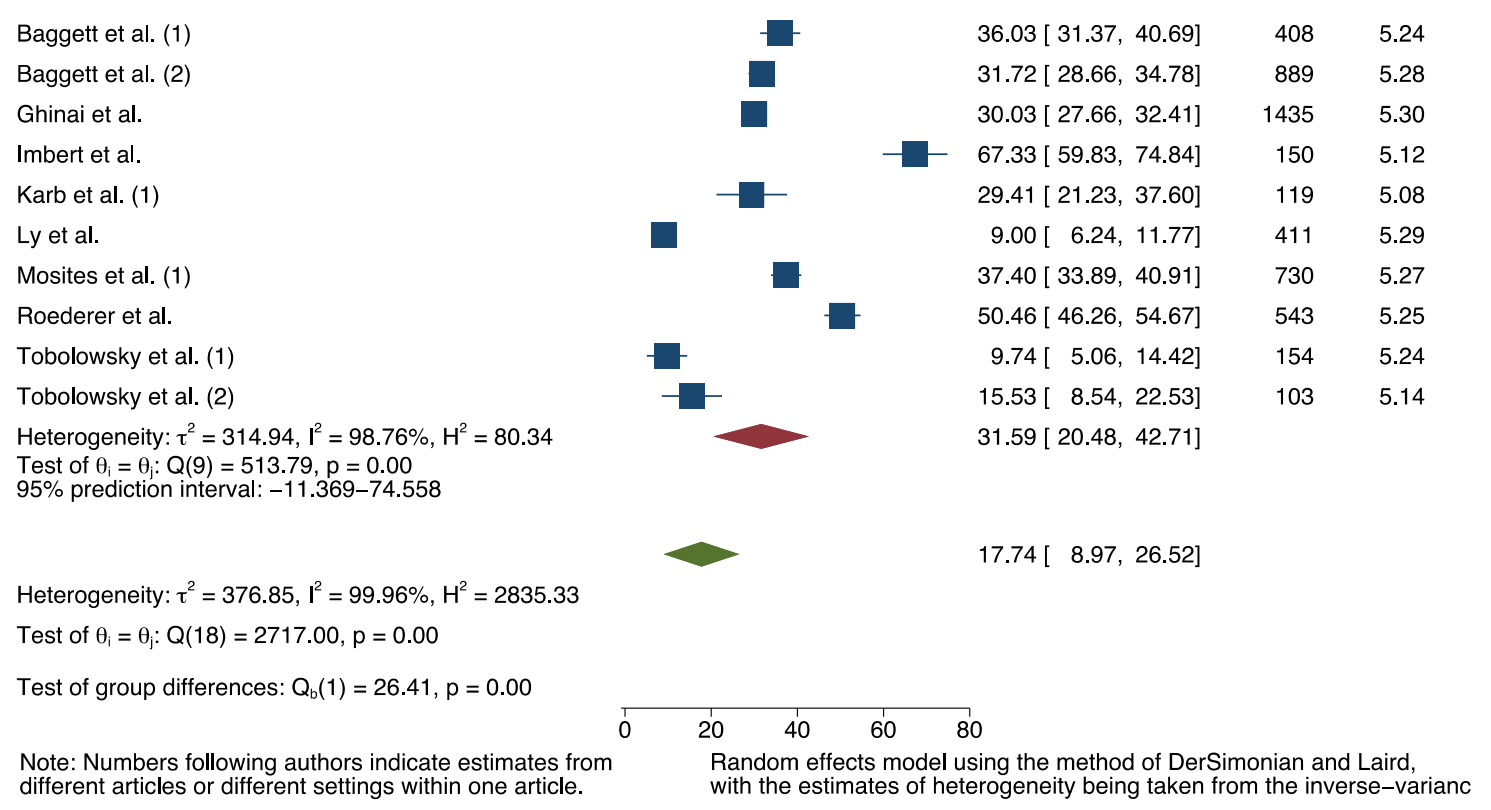

Fig. 2. Continued.

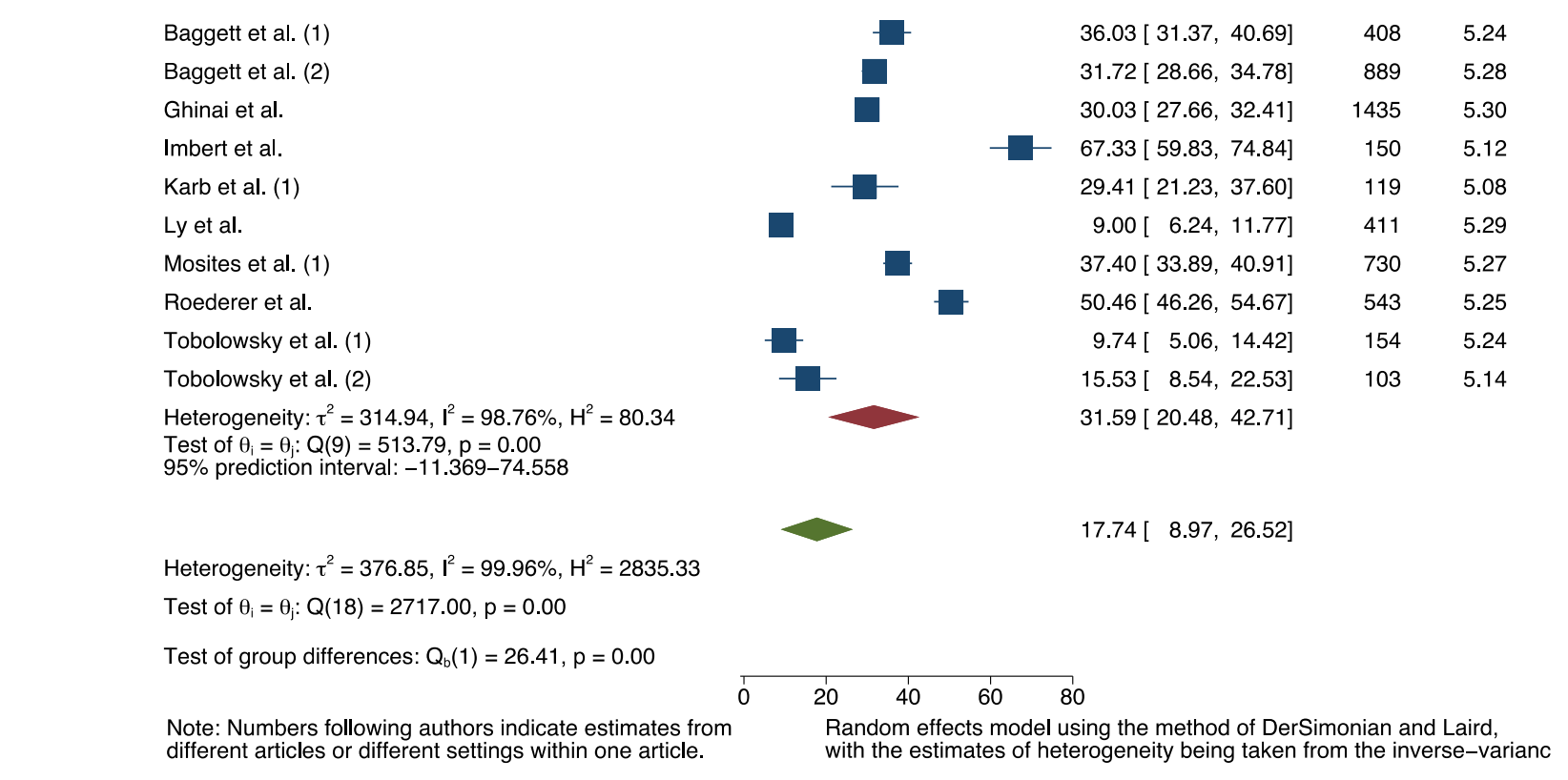

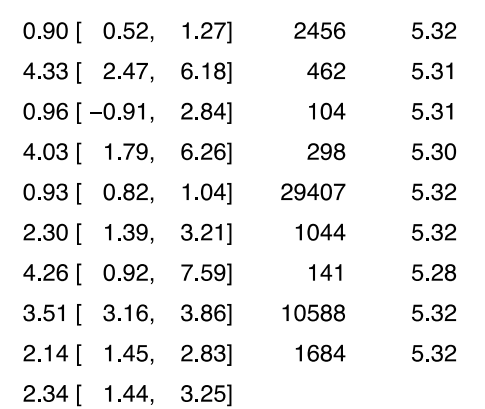

$2.34[1.44,3.25]$ and provided a description of the arising needs (such as substitution therapy and harm reduction services for people with opioid dependence, and ensuring withdrawal is not confused with or masked by a SARS-Cov-2 infection) and information given to more than 1000 sheltered and relocated people.

An ethnographic study conducted in Rio de Janeiro, Brazil, looked at how homeless people lived during the pandemic [60]. Using interviews and document analysis, the authors describe how isolation led to emptying the streets and reducing passers-by, negatively impacting homeless' ways of living survival tactics. Hunger, thirst, absence of places for bathing and for fulfilling physiological needs became apparent and that the actions offered to limit virus dissemination were largely ineffective.

In Barcelona, Spain, Redondo-Sama et al. [61] performed qualitative interviews with social workers in different fields including PEH, and identified the following main difficulties brought about by the pandemic to social work directed at vulnerable groups: general lack of preparedness of social workers, scarcity of PPE, increase in basic demands (food, housing, etc.) for vulnerable groups, closure of dedicated services, and changes in official guidelines and protocols to work in the Covid-19 context.

\subsection{Infection protection and control (IPC) strategies in homeless shelters}

We identified no study quantifying the effectiveness of strategies for IPC among PEH. 11 papers [25,29,37,39,42,47,51,54,56,57,62] discussed strategies for IPC more generally, and one study [35] actively investigated these at 9 shelters. Yoon et al. [35] describe different pandemic preparation measures, e.g., $55.6 \%$ of shelters (5 in 9) discontinued taking in new clients, $77.8 \%$ (7 in 9) created separate isolation areas for PEH with suspected infection and 55.6\% (5 in 9) increased the spacing between individual beds. Accordingly, Roederer et al. [46] found that medium and high crowding, a composite score based on the number of people sharing the room, a sanitary facility, a kitchen and the number of close contacts per day, had the strongest correlation with seropositivity among PEH.

Across all studies, the major strategies discussed as important and necessary were comprehensive and rapid testing, expansion of noncongregate supportive housing for $\mathrm{PEH}$ and, specific strategies for IPC to be taken in congregate settings, e.g. increased spacing between beds, staggered showering and meal schedules, and/or limited staff rotation. O'Shea et al. [63] and Baggett et al.[56] further discussed potential benefits in administrative measures, e.g. collaborating with 


\section{SARS-Cov-2 prevalence} in shelter staff

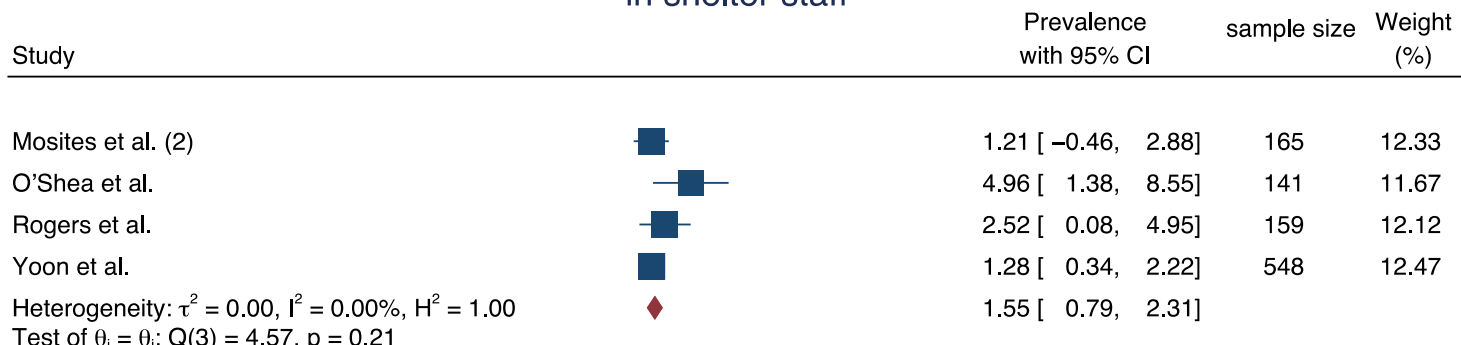

Test of $\theta_{\mathrm{i}}=\theta_{\mathrm{j}}: \mathrm{Q}(3)=4.57, \mathrm{p}=0.21$

$95 \%$ prediction interval: $[-0.116,3.215]$

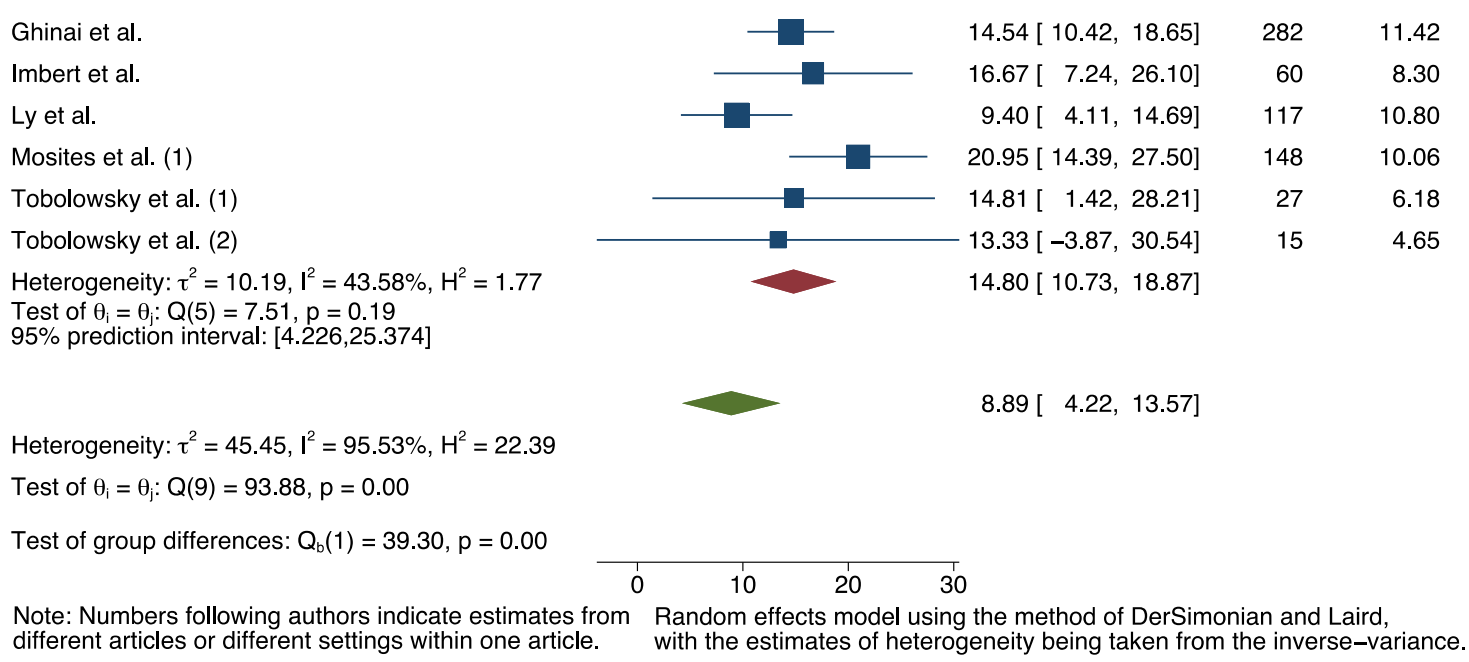

Fig. 3. Forest plot of SARS-Cov-2 prevalence pooled by outbreak situation and in total for staff.

regional laboratories for quick turnaround of test results which enable the isolation of the infected.

Furthermore, Henwood et al. [38] reported that 39\% (207 of 532) of the tenants of supportive housing in Los Angeles considered themselves to be at serious risk for COVID-19 due to a pre-existing condition, 59\% (316 of 532) had a registered mental health diagnosis and $55.3 \%$ ( 294 of 532 ) believed they can shelter in place if needed.

One study reporting about the results of testing 331 senior homeless residents of three shelters in Slovakia[51] did not find any positive case and attributed this result to the implementation of a life island policy, characterized by semi-quarantine, made possible due to incentive and social policies as well as initial testing.

Similarly, Jatt et al. [29], described that the implementation of a widespread surveillance testing strategy has likely prevented asymptomatic transmission of SARS-CoV-2, thereby preventing potential outbreaks of Covid-19 in their study, which included 121 homeless (out of 1781 participants), at an integrated medical campus with tertiary-care center, skilled nursing facility, rehabilitation treatment center, and temporary shelter units.

\section{Discussion}

In this systematic review including a total of 37 empirical studies, we identified a baseline SARS-Cov-2 prevalence of $2.32 \%$ (95\% CI $1.30-3.34 \%$ ) among PEH in homeless shelters, and $1.55 \%$ (95\% Cl $=0.79-2.31 \%)$ among staff. In case of an outbreak situation, these estimates increase to $31.59 \%(95 \% \mathrm{CI}=20.48-42.71 \%)$ among $\mathrm{PEH}$ and $14.80 \%(95 \% \mathrm{Cl}=10 \cdot 73-18.87 \%)$ among staff. For unsheltered $\mathrm{PEH}$, we only identified one study which reported a prevalence of $0.5 \%$.
Specific symptoms, e.g. cough, shortness of breath or fever, were either uncommon or did not differ significantly from the overall tested population of PEH $[16,24,35,36,38,39]$, neither did comorbidities [39] (except for a low-powered study conducted in Belgium [49]). The reviewed evidence, despite being scarce, suggests that hospitalisation, intensive care utilization and mortality rates related to Covid-19 were higher among PEH compared to community dwelling populations [43], and that a considerable proportion of PEH who were tested positive used emergency services (12\%), were hospitalised $(8 \%)$ or died $(1 \%)$ [36].

Evidence on living realities was scarce but suggests that unstable living situations may impede adherence to social distancing practices [64], and that stay at home measures led to empty streets and less passer-bys menacing exisiting survical tactics of PEH [60].

Evidence quantifying the effectiveness of IPC strategies among PEH was only available from modelling studies, indicating high number of infections (cumulative incidence of $49.3 \%$ ) if no interventions were taken, even with low SARS-Cov-2 incidence in the general population [54]. Daily symptom screening with PCR testing of individuals who had positive screening results and the provision of alternative care sites for Covid-19 management were modelled to be the most efficient and cost-saving strategy to tackle the pandemic among PEH [65].

In terms of IPC strategies, 11 studies [29,31,35,37,39,42, $47,48,54,56,57]$ discussed comprehensive and rapid testing including collaboration with regional laboratories for quick turnaround of positive tests, expansion of non-congregate housing and individual strategies in the shelters, e.g. spacing between beds and limited staff rotation, as critical measures to be taken. PEH living in overcrowded shelters were found to have higher odds of seropositivity compared 
Table 3

Research gaps identified.

(A) Lack of data for evaluation of NPIs effectiveness and (un)intended health consequences
$\begin{array}{ll}\text { (1) lack of reliable and separate data on PEH within } & \text { (2) lack of a comprehensive overview of NPIs and } \\ \text { Covid-19 notification systems } & \text { shelter strategies targeting PEH }\end{array}$
(3) lack of understanding of infectious disease spread among PEH, e.g. in homeless shelters

\begin{abstract}
(B) Targeted research into people experiencing rooflessness
While PEH may be deemed as a hard-to-reach population in general, it is essential to differentiate those living in shelters from those sleeping rough. People experiencing rooflessness may be at a less risk of SARS-Cov-2 infection as long as they do not seek congregate shelter but at the same time, they may be the ones experiencing more heavily the challenges of social distancing to mental and social wellbeing associated with the imposed lockdowns.
\end{abstract}

(C) Lack of qualitative research into living realities of PEH

More qualitative research is needed to better understand living realities and particular needs of PEH during the pandemic. This can further kick-start the participation of $\mathrm{PEH}$ in the research process.

(D) Timely updates of the review

With the current infection dynamics and speed of research, timely updates of synthesised information are essential.

to those in low density shelters (OR: $3.4 ; 95 \% \mathrm{CI}: 1.7-6.9, p<0.0001$ ) [46].

Although excluded from this review, we found several reports retrieved from the relevant websites searched providing IPC strategies specifically for staff working in homeless shelters (supplementary material 3 ). These strategies should be adapted to the respective context and enacted to mitigate the spread of SARS-Cov-2 infection among this vulnerable population group. We further identified important research gaps to be addressed by future research (Table 3 ).

Studies providing prevalence estimates were based on PCR testing and some included testing of staff for a complete picture of SARSCov-2 infection in shelters. Overall, the quality of evidence was moderate. Most articles provide little detail on how and why shelters were sampled. Cross-sectional studies may have missed infected patients who do not have enough viral particles yet to be detected in PCR. Only two articles conducted follow-up testing [35,37]. The recruitment of participants was based on accommodation in homeless shelters with little systematic surveying of housing situation and residence type in shelter. This may be of special importance considering the diverse background of PEH and their everyday life, because not all shelters offer accommodation during the day. Most identified studies were monocentric and based in high-income countries raising questions of generalizability especially to middle- and lower-income countries that differ in population demographics, cultural and social dimensions as well as definitions of homelessness.

The qualitative studies offered sufficient insight into their methodology and data analysis. One qualitative article [64] offered little details on study design (including questions on how conversations were guided), details on interviewers and implications for the way interviews progress as well as ethical concerns. Further, most studies did not discuss the relationship between researchers and participants.

Both modelling studies offered insights into their structural and parameter assumptions and methods applied which enable potential replication.

Besides major databases, we searched websites of relevant institutions as well as table of contents of non-indexed journals and consulted the Covid-19 evidence live map of the Norwegian Institute of Public Health. Further, we have used forward and backward reference screening on all identified articles. All steps of the review have been conducted by two reviewers for quality assurance. Finally, we tested for publication bias, both visually through funnel plotting as well as statistically based on Egger et al. [17,18]. Additionally, risk of publication bias might be low as we are investigating prevalence estimates (compared to measures of effect) during the first year of a pandemic of global relevance.

We have used English search terms only, thus might have missed relevant studies in other languages. Nevertheless, we found 11 studies from non-English language countries. As most of the studies focus on North American and European countries, our findings may not be generalizable to other settings than the ones where the studies were conducted, as droplet or potentially airborne transmission may be different in other contexts of social and cultural communication and interaction. Even though we searched several databases and repositories, we might not have detected all relevant studies considering the amount of evidence being generated during the current pandemic. Additionally, we cannot rule out the possibility of publication bias, particularly regarding the baseline prevalence among staff since estimates for this group were not part of these studies' initial objectives.

In order to explore heterogeneity underlying our meta-analyses, we have calculated $95 \%$ confidence intervals. For our baseline estimations for both PEH as well as staff, the heterogeneity was low and ranged $2 \%$ around the estimated mean. For estimations during an outbreak, the prediction intervals covered a broader range of $10 \%$ for staff and $45 \%$ for PEH around their respective estimated mean. This suggests large heterogeneity and caution discussing SARS-Cov-2 attack rates in homeless shelters. As a global systematic review, the shelters included may be defined by different characteristics, e.g. spacing between beds, meal or shower administration, resulting in different attack rates.

As the quality of included studies varies, findings should be considered with caution. Yet, they clearly suggest that PEH are at high risk of being infected with SARS-Cov-2, especially in case of outbreaks in shelters. Potential pathways for transmissions deserving further investigation are the "mobile nature of the community and use of multiple homeless service sites among residents" [37], crowded sleeping arrangements and difficulties in adhering to recommended behavioural interventions due to lack of resources and private space. Furthermore, PEH face serious mental health challenges $[38,53]$ and economic difficulties that prevent them from accessing preventive material and maintaining physical distancing in general [58].

The nature and direction of the infectious disease spread is unclear but staff working at shelters are at increased risk as well, reinforcing the importance of adherence to strategies of IPC in congregate shelters and the expansion of provision of non-congregate housing for PEH.

Due to the absence or low prevalence of symptoms (e.g. fever) at the time of diagnosis of SARS-Cov-2 among PEH [16,24,35,39], symptom screening alone is not suitable, i.e. not sensitive enough for adequately capturing the extent of disease transmission in such high-risk settings. Instead, comprehensive and early testing for timely identification and isolation of the infected, combined with collaboration with regional laboratories for quick turnaround of positive test results might be important strategies to break the virus transmission [35,42].

Finally, against the backdrop of current debates on vaccination strategies it is essential to discuss and evaluate the most suitable vaccination prioritization strategies and outreach campaigns to ensure timely vaccination of people experiencing homelessness, particularly in light of their high mental health burden $[66,67]$ and preventing PEH from avoiding shelter out of fear of infection [53]. 


\section{Declaration of Competing Interest}

The review has been conducted in the scope of the German Competence Net Public Health Covid-19. JS is volunteering (without financial compensation) for a German NGO which provides medical services free of charge for - among others - individuals living in homeless shelters. He further reports membership of the Social Democratic Party of Germany (SPD). The other authors state that they have no competing interests.

\section{Data availability statement}

Detailed review lists can be provided by the corresponding author upon reasonable request.

\section{Funding}

This research did not receive any specific grant from funding agencies in the public, commercial, or not-for-profit sectors.

\section{Authors' contributions}

Conceptualisation: AM, DC, KB

Data curation / Search: Embase - SR; WHO Covid19 - DC; WoS -

SR; websites - DC; NIPH live map - AM; Snowballing: JS

Title and abstract screening: AM, DC

Full-text screening: AM, DC

Quality appraisal: AM, DC, JS, SR

Data extraction: AM, DC

Data-synthesis: AM, DC

Writing of first and final draft: AM, DC

Revision for important intellectual content: KB, JS, SR

\section{Supplementary materials}

Supplementary material associated with this article can be found, in the online version, at doi:10.1016/j.eclinm.2021.101032.

\section{References}

[1] Ayano G, Ayano G, Shumet S, Tesfaw G, Tsegay L. A systematic review and metaanalysis of the prevalence of bipolar disorder among homeless people. BMC Public Health 2020;20:731.

[2] Ayano G, Solomon M, Tsegay L, Yohannes K, Abraha M. A systematic review and meta-analysis of the prevalence of post-traumatic stress disorder among homeless people. Psychiatr Q 2020;91:949-63.

[3] Beijer U, Wolf A, Fazel S. Prevalence of tuberculosis, hepatitis C virus, and HIV in homeless people: a systematic review and meta-analysis. Lancet Infect Dis 2012:12:859-70

[4] Lewer D, Aldridge RW, Menezes D, et al. Health-related quality of life and prevalence of six chronic diseases in homeless and housed people: a cross-sectional study in London and Birmingham, England.. BMJ Open 2019;9. doi: 10.1136 bmjopen-2018-025192.

[5] FEANTSA. European federation of national organisations working with the homeless. Brussels: ETHOS - European Typology on Homelessness and housing exclusion; 2005.

[6] Amore K, Baker M, Howden-Chapman P. The ETHOS definition and classification of homelessness: an analysis. Eur J Homelessness 2011;5:19-37.

[7] Tsai J, Wilson M. COVID-19: a potential public health problem for homeless populations. Lancet Public Heal 2020;5:e186-7.

[8] Maxmen A. Coronavirus is spreading under the radar in US homeless shelters Nature 2020;581:129-30.

[9] Conway B, Truong D, Wuerth K. COVID-19 in homeless populations: unique challenges and opportunities. Future Virol 2020;15:331-4.

[10] Mohsenpour A., Bozorgmehr K., Rohleder S., Stratil J., Costa D. Homelessness and COVID-19: a rapid systematic review. PROSPERO 2020 CRD420201807033. 2020. https://www.crd.york.ac.uk/prospero/display_record.php?ID=CRD42020187033.

[11] Jackson N, Waters E. Criteria for the systematic review of health promotion and public health interventions. Health Promot Int 2005;20:367-74

[12] Borenstein M, Hedges LV, Higgins JPT, Rothstein HR. A basic introduction to fixedeffect and random-effects models for meta-analysis. Res Synth Methods 2010;1:97-111.

[13] IntHout J, Ioannidis JPA, Rovers MM, Goeman JJ. Plea for routinely presenting prediction intervals in meta-analysis. BMJ Open 2016;6:e010247.
[14] Higgins JPT, Thompson SG, Deeks JJ, Altman DG. Measuring inconsistency in meta-analyses. Br Med J 2003:327:557-60.

[15] Hartfield M, Alizon S. Introducing the Outbreak Threshold in Epidemiology. PLoS Pathog 2013;9:e1003277.

[16] Ly TDA, Hoang VT, Goumballa N, et al. Screening of SARS-CoV-2 among homeless people, asylum-seekers and other people living in precarious conditions in Marseille, France, March-April 2020. Int J Infect Dis 2020 2020.05.05.20091934.

[17] Egger M, Smith GD, Schneider M, Minder C. Bias in meta-analysis detected by a simple, graphical test. Br Med J 1997;315:629-34.

[18] Sterne JAC, Egger M. Funnel plots for detecting bias in meta-analysis: guidelines on choice of axis. J Clin Epidemiol 2001;54:1046-55

[19] StatCorp. Stata statistical. 2001.

[20] Nyaga VN, Arbyn M, Aerts M. Metaprop: a Stata command to perform meta-analysis of binomial data. Arch Public Health 2014;72:1-10.

[21] Sterne J, Harbord R, White I. An overview of meta-analysis in stata. United Kingdom Stata users' group meetings 2010 11. Stata Users Group; 2010.

[22] Moher D, Liberati A, Tetzlaff J, et al. Preferred reporting items for systematic reviews and meta-analyses: the PRISMA statement. PLoS Med 2009;6:e1000097.

[23] Mosites E, Parker EM, Clarke KEN, et al. Assessment of SARS-CoV-2 infection prevalence in homeless shelters - four U.S. Cities, March 27-April 15, 2020. MMWR Morb Mortal Wkly Rep 2020;69:521-2.

[24] Baggett TP, Keyes H, Sporn N, Gaeta JM. Prevalence of SARS-CoV-2 infection in residents of a large homeless shelter in Boston. JAMA J Am Med Assoc 2020:323:2191-2.

[25] Ghinai I, Davis ES, Mayer S, et al. Risk factors for severe acute respiratory syndrome coronavirus 2 infection in homeless shelters in Chicago, Illinois - MarchMay 2020. Open Forum Infect Dis 2020;7 ofaa477-ofaa477.

[26] Hickey MD, Imbert E, Glidden DV, et al. Viral suppression not decreased during COVID-19 among people with HIV and unstable housing enrolled in a low-barrier clinic-based program (POP-UP). AIDS 2020 Publish Ah. doi: 10.1097/ qad.0000000000002793.

[27] Han E, Tan MMJ, Turk E, et al. Lessons learnt from easing COVID-19 restrictions: an analysis of countries and regions in Asia Pacific and Europe. Lancet 2020;396:1525-34

[28] Hsu HE, Ashe EM, Silverstein M, et al. Race/ethnicity, underlying medical conditions, homelessness, and hospitalization status of adult patients with COVID-19 at an urban safety-net medical center - Boston, Massachusetts, 2020. MMWR Morb Mortal Wkly Rep 2020;69:864-9.

[29] Jatt LP, Winnett A, Graber CJ, Vallone J, Beenhouwer DO, Goetz MB. Widespread severe acute respiratory coronavirus virus 2 (SARS-CoV-2) laboratory surveillance program to minimize asymptomatic transmission in high-risk inpatient and congregate living settings. Infect Control Hosp Epidemiol 2020;41:1331-4.

[30] Kelly D, Murphy H, Vadlamudi R, et al. Successful public health measures preventing COVID-19 at a Michigan homeless shelter. Infect Control Hosp Epidemiol 2020:1-2

[31] Rogers JH, Link AC, McCulloch D, et al. Characteristics of COVID-19 in homeless shelters : a community-based surveillance study. Ann Intern Med 2021;174:429.

[32] Spinelli MA, Hickey MD, Glidden DV, et al. Viral suppression rates in a safety-net HIV clinic in San Francisco destabilized during COVID-19. AIDS 2020;34:2328-31.

[33] Tucker JS, D’Amico EJ, Pedersen ER, Garvey R, Rodriguez A, Klein DJ. Behavioral health and service usage during the COVID-19 pandemic among emerging adults currently or recently experiencing homelessness. J Adolesc Health 2020;67:603-5.

[34] Marquez H, Ramers C, Northrup A, et al. Response to the coronavirus disease 2019 pandemic among people experiencing homelessness in congregant living settings in San Diego, California. Clin Infect Dis 2020 published online Oct 28. DOI. doi: 10.1093/cid/ciaa1668.

[35] Yoon JC, Montgomery MP, Buff AM, et al. Coronavirus disease 2019 (COVID-19) prevalences among people experiencing homelessness and homelessness service staff during early community transmission in Atlanta, Georgia, April-May 2020. Clin Infect Dis 2020 published online Sept 8. DOI. doi: 10.1093/cid/ciaa1340.

[36] Imbert E, Kinley PM, Scarborough A, et al. Coronavirus disease 2019 outbreak in a San Francisco homeless shelter. Clin Infect Dis 2020 published online Aug 3. DOI. doi: $10.1093 /$ cid/ciaa1071.

[37] Tobolowsky FA, Gonzales E, Self JL, et al. COVID-19 outbreak among three affiliated homeless service sites - King County, Washington, 2020. MMWR Morb Mortal Wkly Rep 2020;69:523-6.

[38] Henwood BF, Redline B, Lahey J. Surveying tenants of permanent supportive housing in skid row about COVID-19. J Health Care Poor Underserved 2020;31:1587-94

[39] Karb R, Samuels E, Vanjani R, Trimbur C, Napoli A. Homeless shelter characteristics and prevalence of SARS-CoV-2. West J Emerg Med 2020;21 2020.05.21.20108985.

[40] Baggett TP, Racine MW, Lewis E, et al. Addressing COVID-19 among people experiencing homelessness: description, adaptation, and early findings of a multiagency response in Boston. Public Health Rep 2020;135:435-41.

[41] Ferguson JM, Jacobs J, Yefimova M, Greene L, Heyworth L, Zulman DM. Virtual care expansion in the Veterans health administration during the COVID-19 pandemic: clinical services and patient characteristics associated with utilization. J Am Med Inform Assoc 2020. doi: 10.1093/jamia/ocaa284.

[42] O'Shea T, Bodkin C, Mokashi V, et al. Pandemic planning in homeless shelters: a pilot study of a coronavirus disease 2019 (COVID-19) testing and support program to mitigate the risk of COVID-19 outbreaks in congregate settings. Clin Infect Dis 2021:72:1639-41.

[43] Richard L, Booth R, Rayner J, Clemens KK, Forchuk C, Shariff SZ. Testing, infection and complication rates of COVID-19 among people with a recent history of 
homelessness in Ontario, Canada: a retrospective cohort study. CMAJ Open 2021:9:E1-9.

[44] Wang L, Ma H, Yiu KCY, et al. Heterogeneity in testing, diagnosis and outcome in SARS-CoV-2 infection across outbreak settings in the Greater Toronto Area, Canada: an observational study. CMAJ Open 2020;8:E627-36.

[45] Ly TDA, Hoang VT, Goumballa N, et al. Variations in respiratory pathogen carriage among a homeless population in a shelter for men in Marseille, France, March-July 2020: cross-sectional 1-day surveys. Eur J Clin Microbiol Infect Dis 2021. doi: 10.1007/s10096-020-04127-9.

[46] Roederer T, Mollo B, Vincent C, et al. Seroprevalence and risk factors of exposure to COVID-19 in homeless people in Paris, France: a cross-sectional study. Lancet Public Health 2021. doi: 10.1016/s2468-2667(21)00001-3.

[47] Ralli M, Morrone A, Arcangeli A, Ercoli L. Asymptomatic patients as a source of transmission of COVID-19 in homeless shelters. Int J Infect Dis 2021;103:243-5.

[48] Ralli M, Cedola C, Urbano S, et al. Assessment of sars-cov-2 infection through rapid serology testing in the homeless population in the city of Rome, Italy. Preliminary results. J Public health Res 2020:9:556-9.

[49] Schrooyen L, Delforge M, Lebout F, Vanbaelen T, Lecompte A, Dauby N. Homeless people hospitalized with COVID-19 in Brussels. Clin Microbiol Infect 2021;27:151-2.

[50] Martin C, Andrés P. Bullón A, et al. COVID pandemic as an opportunity for improving mental health treatments of the homeless people. Int J Soc Psychiatry 2020 20764020950770-20764020950770.

[51] Gombita P, Olah M, Kovac R, et al. Senior Homeless Population was Covid-19 Free in 3 shelter communities after adapting the Life Island model (Note). Clin Soc Work Heal Interv 2020;11:78-9.

[52] Storgaard SF, Eiset AH, Abdullahi F, Wejse C. First wave of COVID-19 did not reach the homeless population in Aarhus. Dan Med J 2020;67 https://search.bvsalud. org/global-literature-on-novel-coronavirus-2019-ncov/resource/en/covidwho1070419NS

[53] Finnigan R. Self-reported impacts of the COVID-19 pandemic for people experiencing homelessness in Sacramento, California. I Soc Distress Homelessness 2021:1-9.

[54] Lewer D, Braithwaite I, Bullock M, et al. COVID-19 among people experiencing homelessness in England: a modelling study. Lancet Respir Med 2020:8:1181-91.

[55] Karb R, Samuels E, Vanjani R, Trimbur C, Napoli A. Homeless shelter characteristics and prevalence of SARS-CoV-2. West J Emerg Med 2020;21:1048-53.
[56] Baggett TP, Racine MW, Lewis E, et al. Addressing COVID-19 among people experiencing homelessness: description, adaptation, and early findings of a multiagency response in Boston. Public Health Rep 2020;135:435-41.

[57] Culhane D., Treglia D., Steif K., et al. Estimated emergency and observational/ quarantine capacity need for the US homeless population related to COVID-19 exposure by county; projected hospitalizations, intensive care units and mortality. 2020 https://escholarship.org/uc/item/9 g0992bm.

[58] Ramaswamy M, Hemberg J, Faust A, et al. Criminal Justice-involved women navigate COVID-19: notes from the field. Health Educ Behav 2020;47:544-8.

[59] Marcus TS, Heese J, Scheibe A, Shelly S, Lalla SX, Hugo JF. Harm reduction in an emergency response to homelessness during South Africa's COVID-19 lockdown. Harm Reduct J 2020;17:60.

60] Paula HC de, Daher DV, Koopmans FF, Faria MG de A, Lemos PFS, Moniz M de A. No place to shelter: ethnography of the homeless population in the COVID-19 pandemic. Rev Bras Enferm 2020;73:e20200489.

[61] Redondo-Sama G, Matulic V, Munté-Pascual A, Vicente I de. Social work during the COVID-19 crisis: responding to urgent social needs. Sustainability 2020;12:116.

[62] Martin C, Andrés P, Bullón A, et al. COVID pandemic as an opportunity for improving mental health treatments of the homeless people. Int J Soc Psychiatry 2021:67:335-43.

[63] O'Shea T, Bodkin C, Mokashi V, et al. Pandemic planning in homeless shelters: a pilot study of a coronavirus disease 2019 (COVID-19) testing and support program to mitigate the risk of COVID-19 outbreaks in congregate settings. Clin Infect Dis 2020;08:8

[64] Ramaswamy M, Hemberg J, Faust A, et al. Criminal justice-involved women navigate COVID-19: notes from the field. Health Educ Behav 2020 1090198120927304

[65] Baggett TP, Scott JA, Le MH, et al. Clinical outcomes, costs, and cost-effectiveness of strategies for adults experiencing sheltered homelessness during the COVID19 Pandemic. JAMA Netw open 2020;3:e2028195.

[66] Mazereel V, Van Assche K, Detraux J, De Hert M. COVID-19 vaccination for people with severe mental illness: why, what, and how? Lancet Psychiatry 2021;8:44450.

[67] De Hert M, Mazereel V, Detraux J, Van Assche K. Prioritizing COVID-19 vaccination for people with severe mental illness. World Psychiatry 2021;20:54-5. 